FACTA UNIVERSITATIS

Series: Mechanical Engineering Vol. 15, $N^{0} 2,2017$, pp. 307 - 313

DOI: 10.22190/FUME170511014M

Original scientific paper

\title{
DETERMINATION OF IMPORTANT PARAMETERS FOR PATENT APPLICATIONS
}

\author{
UDC 911.2:556
}

\author{
Dušan Marković ${ }^{1}$, Dalibor Petković ${ }^{2}$, Vlastimir Nikolić1, \\ Miloš Milovančević ${ }^{1}$, Nebojša Denić ${ }^{3}$ \\ ${ }^{1}$ University of Niš, Faculty of Mechanical Engineering \\ ${ }^{2}$ University of Niš, Pedagogical Faculty in Vranje \\ ${ }^{3}$ Univerzitet of Priština, Faculty of Science and Mathematics, Kosovska Mitrovica
}

\begin{abstract}
This research study is an analysis of patent applications based on different input parameters. Nine patent indicators for describing patent applications are retrieved from the World Bank database. The method of ANFIS (adaptive neuro fuzzy inference system) is applied to selecting the most important parameters for patent applications. The inputs are: charges for the use of intellectual property for payments and receipts, research and development expenditure, trademark applications for residents and nonresidents, researchers in research and development $(R \& D)$, technicians in $R \& D$ and high-technology exports. As the ANFIS outputs, patent applications for nonresidents and residents are considered. The results show that the combination of research and development expenditure and technicians in $R \& D$ is the most influential combination of input parameters for patent applications.
\end{abstract}

Key Words: ANFIS, Patent Applications, Research, Development

\section{INTRODUCTION}

Since the development of new technologies is rapid and the knowledge of economics has increased, intangible assets are now more significant than before. Patents have the main role in intangible assets. They are the main outcome of research and development and demonstrate the capability of innovation. Companies are influenced by patent applications because of reputation and revenue. Patents also present an essential issue in engineering management, technology management and finance management.

Received May 11, 2017 / Accepted June 26, 2017

Corresponding author: Dalibor Petković

Pedagogical Faculty in Vranje, Partizanska 14, 17500 Vranje, Serbia

E-mail:dalibortc@gmail.com

C 2017 by University of Niš, Serbia | Creative Commons Licence: CC BY-NC-ND 
Several algorithms have been thus far presented for analyzing patent performance [1, $2,3]$. The investigation [4] proposed a patent portfolio-based approach for assessing potential research and development $(\mathrm{R} \& \mathrm{D})$ partners that could consider the inter-partner resource fit in the assessment process. The study [5] investigated commercial application scenarios using patent analysis where five scenarios of application of patented commercial technology were obtained. An automatic patent quality analysis and classification system was developed in [6], where experimental results showed that the proposed system could capture the analysis effectively compared with the traditional manpower approach. The results from the article [7] showed that strengthening patent protection on horizontal R\&D promotes vertical innovation (quality improvement) but hinders horizontal innovation (variety expansion). The investigation [8] showed that an increasing degree of competition enhances innovation and patent applications, which helps firms appropriating part of the benefits of their R\&D investments. The article [9] showed that the later the timing of the patent, the higher the innovation performance, while under low uncertainty there was an early-mover advantage.

In order to overcome high nonlinearity in patent applications models [10] in this study a soft computing method was applied. When structuring predictive models, it is crucial to include the most influential variables and discard the redundant and non-informative predictors. Correct variable selection will result in increased model predictability and interpretability. In this paper, we use a soft computing approach to select the most influential variables for patent applications. The Adaptive Neuro-fuzzy Inference Technique (ANFIS) [11-15] is applied to the available data sets to select the predominant model variables.

\section{MATERIALS AND METHOD}

Table 1 shows nine input and two output parameters used in this research. The patent data is used from the World Bank database. The first and second input parameters represent charges for the use of intellectual property for payments and recipients, respectively, between residents and nonresidents for the authorized use of proprietary rights (such as patents, trademarks, copyrights, industrial processes and designs including trade secrets, and franchises) and for the use, through licensing agreements, of produced originals or prototypes (such as copyrights on books and manuscripts, computer software, cinematographic works, and sound recordings) and related rights (such as those for live performances and television, cable, or satellite broadcast). The data for the first input parameter are in US dollars. The third input parameter represents expenditures for research and development for current and capital expenditures (both public and private) on creative work undertaken systematically to increase knowledge, including knowledge of humanity, culture, and society, and the use of knowledge for new applications. The fourth input parameter represents trademark applications filed for applications to register a trademark with a national or regional Intellectual Property (IP) office. A trademark is a distinctive sign which identifies certain goods or services as those produced or provided by a specific person or enterprise. A trademark provides protection to the owner of the mark by ensuring the exclusive right to use it to identify goods or services, or to authorize another to use it in return for payment. The period of protection varies, but a trademark can be renewed indefinitely beyond the time limit on payment of additional fees. It 
represents direct nonresident trademark applications for those filed by applicants from abroad directly at a given national IP office. The fifth parameter represents direct resident trademark applications for those filed by domestic applicants directly at a given national IP office. The sixth parameter represents the total trademark applications for those filed by domestic applicants directly at a given national IP office. The seventh input parameter represents researchers in research and development (R\&D), which are professionals engaged in the conception or creation of new knowledge, products, processes, methods, or systems and in the management of the projects concerned. $\mathrm{PhD}$ students engaged in R\&D are included. The eighth input parameter represents technicians in $R \& D$ and equivalent staff, namely the people whose main tasks require technical knowledge and experience in engineering, physical and life sciences (technicians), or social sciences and humanities (equivalent staff). They participate in R\&D by performing scientific and technical tasks involving the application of concepts and operational methods, normally under the supervision of researchers. The ninth input parameter represents hightechnology exports which are products with high R\&D intensity, such as in aerospace, computers, pharmaceuticals, scientific instruments, and electrical machinery. The data are in US dollars.

The first output parameter is patent applications of nonresidents for worldwide patent applications filed through the Patent Cooperation Treaty procedure or with a national patent office for exclusive rights for an invention - a product or process that provides a new way of doing something or offers a new technical solution to a problem. A patent provides protection for the invention to the owner of the patent for a limited period, generally 20 years. The second output represents patent applications of residents for worldwide patent applications filed through the Patent Cooperation Treaty procedure or with a national patent office for exclusive rights for an invention.

Table 1 Input parameters for patent applications

\begin{tabular}{cl}
\hline Inputs & Names \\
\hline 1 & Charges for the use of intellectual property, payments (current US\$) \\
2 & Charges for the use of intellectual property, receipts (current US\$) \\
3 & Research and development expenditure (\% of GDP) \\
4 & Trademark applications, direct nonresident \\
5 & Trademark applications, direct resident \\
6 & Trademark applications, total \\
7 & Researchers in R\&D (per million people) \\
8 & Technicians in R\&D (per million people) \\
9 & High-technology exports (current US\$) \\
\hline
\end{tabular}

An ANFIS model will be established in this study to estimate the most important parameters for patent applications in Serbia. The hybrid learning algorithms are applied to identify the parameters in the ANFIS architectures. A fuzzy inference system in the MATLAB software is employed in the whole process of the ANFIS training and evaluation. 


\section{RESULTS}

The input parameters with the lowest RMSE values have the most relevance in regard to the outputs. In other words, the input parameter with the smallest RMSE values has the most influence for the patent applications. The selection of the combinations of the two parameters is also performed in order to find the optimal combination of the two parameters that are of the greatest influence on the patent applications. Since the results for some input combinations are redundant, Tables 2-3 present only some of the selected input coronations (combinations, correlations?) of the two parameters. Table 2 presents the input parameters influence on the prediction of patent applications in Serbia for nonresidents. Accordingly, Table 3 presents the input parameters influence on the prediction of patent applications in Serbia for residents. According to the results in Table 2 one can conclude that the input parameter 7 (researchers in R\&D (per million people)) is the most influential for patent applications in Serbia for nonresidents. On the contrary, the RMSE values for input parameter 1 (charges for the use of intellectual property, payments (current US\$)) have the smallest influence for the prediction of patent applications in Serbia for nonresidents. Table 2 shows a part of two input combinations since the results for other combinations are redundant. According to the results, one can see that the input combination of parameter 3 and 8 (research and development expenditure (\% of GDP) and technicians in R\&D (per million people)) has the largest influence on patent applications in Serbia for nonresidents. Table 3 shows that the same parameter has the highest influence for patent applications in Serbia for residents also.

Table 2 Input parameters RMSE values for the prediction of patent applications in Serbia for nonresidents

\begin{tabular}{|c|c|}
\hline One input & Two inputs \\
\hline $1-\mathrm{RMSE}=78 \times 10^{10}$ & $3,4-\mathrm{RMSE}=0.1120$ \\
\hline $2-\mathrm{RMSE}=51 \times 10^{7}$ & $3,5-\mathrm{RMSE}=0.0213$ \\
\hline $3-\mathrm{RMSE}=8.7630$ & $3,6-\mathrm{RMSE}=0.6992$ \\
\hline $4-\mathrm{RMSE}=3.6590$ & $3,7-\mathrm{RMSE}=0.0127$ \\
\hline 5 - RMSE $=1.3894$ & $3,8-\mathrm{RMSE}=0.0005$ \\
\hline $6-\mathrm{RMSE}=8.6900$ & $4,5-\mathrm{RMSE}=0.5469$ \\
\hline 7 - RMSE $=0.0203$ & 4, 6 - RMSE $=0.7986$ \\
\hline 8 - RMSE=22.9083 & $4,7-\mathrm{RMSE}=0.2182$ \\
\hline \multirow[t]{7}{*}{$9-\mathrm{RMSE}=21 \times 10^{8}$} & $4,8-\mathrm{RMSE}=0.1335$ \\
\hline & $5,6-\mathrm{RMSE}=0.4849$ \\
\hline & $5,7-\mathrm{RMSE}=0.0026$ \\
\hline & $5,8-\mathrm{RMSE}=0.0229$ \\
\hline & $6,7-\mathrm{RMSE}=0.3702$ \\
\hline & $6,8-\mathrm{RMSE}=0.8187$ \\
\hline & $7,8-\mathrm{RMSE}=0.0055$ \\
\hline
\end{tabular}

Table 3 Input parameters RMSE values for the prediction of patent applications in Serbia for residents

\begin{tabular}{ll}
\hline One input & Two inputs \\
\hline 1 - RMSE $=251 \times 10^{10}$ & $3,4-$ RMSE $=0.7572$ \\
2 - RMSE $=19 \times 10^{8}$ & $3,5-$ RMSE $=0.0805$ \\
3 - RMSE $=5.8842$ & $3,6-$ RMSE $=2.7461$ \\
- RMSE $=47.7747$ & $3,7-$ RMSE $=0.0466$ \\
5 - RMSE $=6.5772$ & $3,8-$ RMSE $=0.0018$ \\
6 - RMSE $=21.5403$ & $4,5-$ RMSE $=1.9533$ \\
7 - RMSE $=0.0179$ & $4,6-$ RMSE $=1.7458$ \\
8 - RMSE $=65.9266$ & $4,7-$ RMSE $=0.7052$ \\
9 - RMSE $=45 \times 10^{10}$ & $4,8-$ RMSE $=0.4249$ \\
& $5,6-$ RMSE $=1.7116$ \\
& $5,7-$ RMSE $=0.0073$ \\
& $5,8-$ RMSE $=0.0826$ \\
& $6,7-$ RMSE $=1.2785$ \\
& $6,8-$ RMSE $=3.3914$ \\
& $7,8-$ RMSE $=0.0305$ \\
\hline
\end{tabular}


According to the results in Table 4, the input parameter 5 (trademark applications, direct resident) is the most influential for the prediction of patent applications in Croatia for nonresidents. On the contrary, the training error for input parameter 9 (high-technology exports (current US\$)) has the smallest influence for the prediction of patent applications in Croatia for nonresidents.

According to the results in Table 5, one can see the same input combination of parameters 3 and 8 (research and development expenditure (\% of GDP) and technicians in R\&D (per million people)) as in the case of Serbia with the largest influence on the prediction of patent applications in Croatia for nonresidents as well. Table 5 presents the results for parameters selection for the prediction of patent applications in Croatia for residents. Thus, it is obvious, that the only difference between the results presented in Table 4 and Table 5 is a single input parameter influence. The most influential parameter for patent applications in Croatia for residents is parameter 4 (trademark applications, direct nonresident).

Table 4 Input parameters RMSE values for the Table 5 Input parameters RMSE values for prediction of patent applications in Croatia for nonresidents

\begin{tabular}{ll}
\hline One input & Two inputs \\
\hline $1-\mathrm{RMSE}=38 \times 10^{10}$ & $3,4-\mathrm{RMSE}=0.6246$ \\
$2-\mathrm{RMSE}=22 \times 10^{10}$ & $3,5-\mathrm{RMSE}=0.0693$ \\
$3-\mathrm{RMSE}=9.3460$ & $3,6-\mathrm{RMSE}=2.1536$ \\
$4-\mathrm{RMSE}=0.9596$ & $3,7-\mathrm{RMSE}=0.0469$ \\
$5-\mathrm{RMSE}=0.2246$ & $3,8-\mathrm{RMSE}=0.0070$ \\
$6-\mathrm{RMSE}=4.2449$ & $3,9-\mathrm{RMSE}=0.5223$ \\
$7-\mathrm{RMSE}=0.9240$ & $4,6-\mathrm{RMSE}=2.1184$ \\
$8-\mathrm{RMSE}=1.1260$ & $4,7-\mathrm{RMSE}=0.5094$ \\
$9-\mathrm{RMSE}=188 \times 10^{10}$ & $4,8-\mathrm{RMSE}=2.1156$ \\
& $4,9-\mathrm{RMSE}=1.3059$ \\
& $5,6-\mathrm{RMSE}=0.2419$ \\
& $5,7-\mathrm{RMSE}=0.0218$ \\
& $5,8-\mathrm{RMSE}=1.0865$ \\
& $5,9-\mathrm{RMSE}=2.9935$ \\
& $6,8-\mathrm{RMSE}=0.0488$ \\
\hline
\end{tabular}
the prediction of patent applications in Croatia for residents

\begin{tabular}{ll}
\hline One input & Two inputs \\
\hline $1-\mathrm{RMSE}=21 \times 10^{10}$ & $3,4-\mathrm{RMSE}=0.4310$ \\
$2-\mathrm{RMSE}=18 \times 10^{10}$ & $3,5-\mathrm{RMSE}=0.0476$ \\
$3-\mathrm{RMSE}=2.1498$ & $3,6-\mathrm{RMSE}=0.8482$ \\
$4-\mathrm{RMSE}=0.3904$ & $3,7-\mathrm{RMSE}=0.0338$ \\
$5-\mathrm{RMSE}=0.6700$ & $3,8-\mathrm{RMSE}=0.0097$ \\
$6-\mathrm{RMSE}=2.0379$ & $3,9-\mathrm{RMSE}=1.0007$ \\
$7-\mathrm{RMSE}=0.6028$ & $4,5-\mathrm{RMSE}=0.7065$ \\
$8-\mathrm{RMSE}=1.2072$ & $4,6-\mathrm{RMSE}=0.2872$ \\
$9-\mathrm{RMSE}=1063 \times 10^{10}$ & $4,7-\mathrm{RMSE}=1.2742$ \\
& $4,8-\mathrm{RMSE}=0.3427$ \\
& $4,9-\mathrm{RMSE}=0.1697$ \\
& $5,6-\mathrm{RMSE}=0.0292$ \\
& $5,7-\mathrm{RMSE}=0.1646$ \\
& $5,9-\mathrm{RMSE}=4.0226$ \\
& $6,7-\mathrm{RMSE}=0.0627$ \\
\hline
\end{tabular}

Table 6 shows the results for parameters influence on patent applications in Hungary and the results are the same as for Croatia and Serbia, except for the single parameter influence on the prediction of patent applications.

For nonresident patent applications in Hungary the most influential parameter is the total trademark applications, while for resident patent applications in Hungary the most influential parameter is the direct nonresident trademark applications, direct nonresident (Table 7). 
Table 6 Input parameters RMSE values for the Table 7 Input parameters RMSE values for prediction of patent applications in Hungary for nonresidents

\begin{tabular}{ll}
\hline One input & Two inputs \\
\hline $1-\mathrm{RMSE}=44 \times 10^{10}$ & $3,4-\mathrm{RMSE}=1.2792$ \\
$2-\mathrm{RMSE}=218 \times 10^{13}$ & $3,5-\mathrm{RMSE}=0.2820$ \\
$3-\mathrm{RMSE}=94.9878$ & $3,6-\mathrm{RMSE}=6.4223$ \\
$4-\mathrm{RMSE}=9.5912$ & $3,7-\mathrm{RMSE}=0.0726$ \\
$5-\mathrm{RMSE}=128.6648$ & $3,8-\mathrm{RMSE}=0.0142$ \\
$6-\mathrm{RMSE}=5.4916$ & $3,9-\mathrm{RMSE}=1.2275$ \\
$7-\mathrm{RMSE}=61.7852$ & $4,5-\mathrm{RMSE}=3.8079$ \\
$8-\mathrm{RMSE}=34.6907$ & $4,6-\mathrm{RMSE}=0.5635$ \\
$9-\mathrm{RMSE}=102 \times 10^{14}$ & $4,7-\mathrm{RMSE}=0.1682$ \\
& $4,8-\mathrm{RMSE}=1.1733$ \\
& $4,9-\mathrm{RMSE}=0.6462$ \\
& $5,6-\mathrm{RMSE}=0.5721$ \\
& $5,7-\mathrm{RMSE}=6.1736$ \\
& $6,7-\mathrm{RMSE}=4.6757$ \\
& $6,8-\mathrm{RMSE}=0.1440$ \\
\hline
\end{tabular}
the prediction of patent applications in Hungary for residents

\begin{tabular}{ll}
\hline One input & Two inputs \\
\hline 1 - RMSE $=122 \times 10^{10}$ & $3,4-\mathrm{RMSE}=1.7950$ \\
2 - RMSE $=31 \times 10^{14}$ & $3,5-\mathrm{RMSE}=0.1559$ \\
$3-\mathrm{RMSE}=16.6644$ & $3,6-\mathrm{RMSE}=9.1210$ \\
$4-\mathrm{RMSE}=6.5445$ & $3,7-\mathrm{RMSE}=0.0916$ \\
$5-\mathrm{RMSE}=15.292$ & $3,8-\mathrm{RMSE}=0.0107$ \\
$6-\mathrm{RMSE}=13.0220$ & $4,5-\mathrm{RMSE}=2.2457$ \\
$7-\mathrm{RMSE}=17.9915$ & $4,6-\mathrm{RMSE}=6.4263$ \\
$8-\mathrm{RMSE}=19.2941$ & $4,7-\mathrm{RMSE}=0.5974$ \\
9 - RMSE $=175 \times 10^{14}$ & $4,8-\mathrm{RMSE}=0.2337$ \\
& $5,6-\mathrm{RMSE}=2.2104$ \\
& $5,7-\mathrm{RMSE}=0.1625$ \\
& $5,8-\mathrm{RMSE}=0.0979$ \\
& $5,9-\mathrm{RMSE}=8.5541$ \\
& $6,7-\mathrm{RMSE}=6.6236$ \\
& $6,8-\mathrm{RMSE}=0.2204$ \\
\hline
\end{tabular}

\section{CONCLUSION}

Patents are intangible assets as well as the main outcome of research and development that demonstrate the capability of innovation. In this study the methodology is employed to determine the most influential parameters for patent applications. The Adaptive Neurofuzzy Inference Technique (ANFIS) is applied to the available data sets to select the predominant model variables. The results show that the combination of research and development expenditure and technicians in R\&D is the most influential combination of input parameters for patent applications according to the prediction error of the ANFIS methodology.

\section{REFERENCES}

1. Zhang, S., Yuan, C.C., Chang, K.C., Ken, Y., 2012, Exploring the nonlinear effects of patent $H$ index, patent citations, and essential technological strength on corporate performance by using artificial neural network, Journal of informetrics, 6(4), pp.485-495.

2. Lai, Y.H., Che, H.C., 2009, Modeling patent legal value by Extension Neural Network, Expert Systems with Applications, 36(7), pp.10520-10528.

3. Altuntas, S., Dereli, T., Kusiak, A., 2015, Forecasting technology success based on patent data, Technological Forecasting and Social Change, 96, pp.202-214.

4. Song, B., Seol, H., Park, Y., 2016, A patent portfolio-based approach for assessing potential R\&D partners: An application of the Shapley value, Technological Forecasting and Social Change, 103, pp.156-165.

5. Hsu, C.W., Chang, P.L., Hsiung, C.M., Lin, C.Y., 2014, Commercial application scenario using patent analysis: Fermentative hydrogen production from biomass, International Journal of Hydrogen Energy, 39(33), pp.19277-19284.

6. Wu, J.L., Chang, P.C., Tsao, C.C., Fan, C.Y., 2016, A patent quality analysis and classification system using self-organizing maps with support vector machine, Applied Soft Computing, 41, pp.305-316. 
7. Niwa, S., 2016. Patent claims and economic growth, Economic Modelling, 54, pp.377-381.

8. Blazsek, S., Escribano, A., 2016, Patent propensity, $R \& D$ and market competition: Dynamic spillovers of innovation leaders and followers, Journal of Econometrics, 191(1), pp.145-163.

9. Kim, B., Kim, E., Miller, D.J., Mahoney, J.T., 2016, The impact of the timing of patents on innovation performance, Research Policy, 45(4), pp.914-928.

10. Hingley, P., Nicolas, M., 2004, Methods for forecasting numbers of patent applications at the European Patent Office, World Patent Information, 26(3), pp.191-204.

11. Jang, J.S., 1993, ANFIS: adaptive-network-based fuzzy inference system, IEEE transactions on systems, man, and cybernetics, 23(3), pp.665-685.

12. Zhang, Y.L., Lei, J.H., 2017, Prediction of Laser Cutting Roughness in Intelligent Manufacturing Mode Based on ANFIS, Procedia Engineering, 174, pp.82-89.

13. Pusat, S., Akkoyunlu, M.T., Pekel, E., Akkoyunlu, M.C., Özkan, C., Kara, S. S., 2016, Estimation of coal moisture content in convective drying process using ANFIS, Fuel Processing Technology, 147, pp.12-17.

14. Akkaya, E., 2016, ANFIS based prediction model for biomass heating value using proximate analysis components, Fuel, 180, pp.687-693.

15. Tan, Y., Shuai, C., Jiao, L., Shen, L., 2017, An adaptive neuro-fuzzy inference system (ANFIS) approach for measuring country sustainability performance, Environmental Impact Assessment Review, 65, pp.29-40. 